\title{
Effects of 3-Week Work-Matched High-Intensity Intermittent Cycling Training with Different Cadences on $\mathrm{VO}_{2 \max }$ in University Athletes
}

\author{
Nobuyasu Tomabechi ${ }^{1,2, *}$, Kazuki Takizawa ${ }^{3}$, Keisuke Shibata ${ }^{2,4}$ and Masao Mizuno ${ }^{5}$ \\ 1 Sports Training Center, Nippon Sport Science University, Setagaya, Tokyo 158-8508, Japan \\ 2 Graduate School of Education, Hokkaido University, Sapporo, Hokkaido 060-0811, Japan \\ 3 Institute of Physical Development Research, Sapporo, Hokkaido 060-0061, Japan; takizawa@pd-r.org \\ 4 Department of Sustainable Agriculture, College of Agriculture, Food and Environment Sciences, \\ Rakuno Gakuen University, Ebetsu, Hokkaido 069-0836, Japan; k-shibata@rakuno.ac.jp \\ 5 Faculty of Education, Hokkaido University, Sapporo, Hokkaido 060-0811, Japan; \\ mizuno@edu.hokudai.ac.jp \\ * Correspondence: nobuyasu.tomabechi@gmail.com; Tel.: +81-3- 5706-0900
}

Received: 27 August 2018; Accepted: 28 September 2018; Published: 29 September 2018

\begin{abstract}
The aim of this study is to clarify the effects of 3-week work-matched high-intensity intermittent cycling training (HIICT) with different cadences on the $\mathrm{VO}_{2 \mathrm{max}}$ of university athletes. Eighteen university athletes performed HIICT with either $60 \mathrm{rpm}(n=9)$ or $120 \mathrm{rpm}(n=9)$. The HIICT consisted of eight sets of $20 \mathrm{~s}$ exercise with a $10 \mathrm{~s}$ passive rest between each set. The initial training intensity was set at $135 \%$ of $\mathrm{VO}_{2 \text { max }}$ and was decreased by $5 \%$ every two sets. Athletes in both groups performed nine sessions of HIICT during a 3-week period. The total workload and achievement rate of the workload calculated before experiments in each group were used for analysis. $\mathrm{VO}_{2 m a x}$ was measured pre- and post-training. After 3 weeks of training, no significant differences in the total workload and the achievement rate of the workload were found between the two groups. $\mathrm{VO}_{2 \max }$ similarly increased in both groups from pre- to post-training $(p=0.016)$, with no significant differences between the groups $(p=0.680)$. These results suggest that cadence during HIICT is not a training variable affecting the effect of $\mathrm{VO}_{2 m a x}$.
\end{abstract}

Keywords: aerobic capacity; graded-exercise test; total workload

\section{Introduction}

High-intensity intermittent (or interval) training (HIIT) is considered a time-efficient exercise strategy, due to its superior effect toward improving $\mathrm{VO}_{2 \mathrm{max}}$ in less time than low- or moderate-intensity continuous exercise [1,2]. In addition, HIIT can increase $\mathrm{VO}_{2 \max }$ in a short period (2-4 weeks) [3-9]. Since the total available time for training is often limited for athletes, it is important to determine the more effective HIIT methodology for increasing $\mathrm{VO}_{2 \mathrm{max}}$ in a short period.

HIIT with the use of a cycle ergometer is considered a safe method of training, and cadence may be a training variable that affects the chronic effect of $\mathrm{VO}_{2 m a x}$. In previous studies, various training modes, such as cycling, running, aquatic treadmill running, jump rope, swimming, and kettlebell training, have been attempted [10]. Results showed that the stress on the anterior cruciate ligament was lower during cycling exercise [11,12]. In addition, cycling exercise was found to be associated with fewer eccentric contraction phases, which cause muscle damage, when compared to running [13]. Thus, HIIT by using a cycle ergometer can increase $\mathrm{VO}_{2 \mathrm{max}}$ more safely. The cadence used during work-matched cycling training may be a training variable that affects the chronic effect of $\mathrm{VO}_{2 \max }$ under relative intensity (e.g., $\% \mathrm{VO}_{2 \max }$ ) and the length of time applied to the exercise-matched 
condition. The workload during cycling exercise is a product of load $(\mathrm{kp})$ and cadence (rpm). Therefore, high-intensity intermittent cycling training (HIICT) can be performed either with high load/low cadence or with low load/high cadence under the workload, relative intensity (e.g., $\% \mathrm{VO}_{2 \max }$ ), and exercise time-matched conditions [14]. Many previous studies reported that oxygen uptake $\left(\mathrm{VO}_{2}\right)$ during work-matched cycling exercise increases more significantly in high-cadence cycling than in low-cadence cycling (35-110 rpm) due to the elevated internal workload of active muscles [15-20]. Thus, work-matched cycling exercise with a high cadence may have a higher actual intensity than cycling exercise with a low cadence, even though the relative intensity (e.g., $\% \mathrm{VO}_{2 \max }$ ) is equal. Matsuo et al. reported that high-intensity interval training improves $\mathrm{VO}_{2 \max }$ more significantly than moderate-intensity training due to an increase in left ventricular mass and stroke volume [21]. Therefore, it can be speculated that HIICT with a high cadence can improve $\mathrm{VO}_{2 \max }$ more significantly than HIICT with a low cadence. In contrast, Paton et al. reported that high-intensity interval training with a low cadence significantly improved $\mathrm{VO}_{2 \max }$ compared to that of a high cadence in male cyclists [22]. However, workload was not matched in this study. Since the workload affects the chronic effect of $\mathrm{VO}_{2 \max }$ [23], the effect of the difference in cadence on $\mathrm{VO}_{2 \max }$ should be examined under work-matched conditions.

The aim of this study, therefore, was to examine whether 3-week work-matched HIICT with a high cadence (120 rpm) can significantly improve $\mathrm{VO}_{2 \max }$ compared to HIICT with a low cadence (60 rpm) in university athletes.

\section{Materials and Methods}

\subsection{Experimental Design}

Participants were assigned to one of two groups according to their workload of HIICT, calculated based on pre-training $\mathrm{VO}_{2 \max }$. One group of participants performed HIICT with a low cadence of $60 \mathrm{rpm}(n=9$, age: $20.1 \pm 0.8$ years, height: $174.6 \pm 4.8 \mathrm{~cm}$, body weight: $65.4 \pm 3.9 \mathrm{~kg})$ and the other group of participants performed HIICT with a high cadence of $120 \mathrm{rpm}(n=9$, age: $20.0 \pm 1.0$ years, height: $173.2 \pm 5.3 \mathrm{~cm}$, body weight: $64.4 \pm 6.3 \mathrm{~kg}$ ). HIICT was performed by both groups in nine sessions during a 3-week period and at least twice per week in order not to bias the number of sessions per week. In both groups, training load was increased by $2.5 \%$ after every three sessions. All training sessions were supervised by investigators with expert knowledge of HIICT. $\mathrm{VO}_{2 \max }$ measurement during the graded-exercise test using a cycle ergometer was carried out pre- and post-training. All measurements for each participant were performed at approximately the same time of day $( \pm 2.5 \mathrm{~h})$ to take into consideration the circadian rhythm.

\subsection{Participants}

A total of 21 Japanese male university athletes were initially recruited. However, three participants could not complete the training due to injuries unrelated to the experiment. Thus, data from 18 participants were used for further analysis. All participants practiced exercise at least twice per week and belonged to the university volleyball $(n=8)$, soccer $(n=3)$, soft tennis $(n=3)$, ultimate $(n=2)$, badminton $(n=1)$, and sailing $(n=1)$ teams. Participants did not habitually perform any physical training, except for practice for their respective sports; furthermore, no participants had performed resistance training for the lower body more than two times per week during the previous 6 months or performed any cycling training for a competitive race. All participants were informed about the potential risks of experiments and provided written consent prior to participation. This study was approved by the Ethics Committee of Faculty of Education, Hokkaido University (approval number: 17-24). 


\section{3. $V O_{2 \max }$}

The graded-exercise test using a cycle ergometer (Powermax-VII, Combi Wellness, Tokyo, Japan) was performed to determine $\mathrm{VO}_{2 \max }$ and relative intensity of the HIICT. The test was initiated at $60 \mathrm{~W}$, followed by $30 \mathrm{~W}$ increases every 3 min until each participant was unable to maintain a cadence of $60 \mathrm{rpm}$. The cadence during the test was controlled by a metronome and was displayed on a screen. During the test, $\mathrm{VO}_{2}$ was measured every $10 \mathrm{~s}$ using mixing chamber methods with a respiratory gas analyzer (VO2000, S\&ME Co. Ltd., Tokyo, Japan) and the peak value was defined as $\mathrm{VO}_{2 \max }$ [24-26].

\subsection{High-Intensity Intermittent Cycling Training}

In all training sessions, the HIICT was performed by using a cycle ergometer (Powermax-VII, Combi Wellness, Tokyo, Japan) following a warm-up at $90 \mathrm{~W}$ for $10 \mathrm{~min}$ and a rest period of $3 \mathrm{~min}$. The initial training intensity of the HIICT was set at $135 \%$ of $\mathrm{VO}_{2 \max }$ and was decreased by $5 \%$ every two sets. HIICT consisted of eight sets of $20 \mathrm{~s}$ pedaling, with a $10 \mathrm{~s}$ passive rest between each set. This protocol was conducted according to the results of our pilot study that was, in turn, based on previous studies $[3,27,28]$. Participants were instructed to maintain a cadence of either $60 \mathrm{rpm}$ or $120 \mathrm{rpm}$, which was controlled by the value displayed on the screen and a metronome during each session. After the HIICT, participants performed a cool down at $90 \mathrm{~W}$ for $5 \mathrm{~min}$ in all training sessions. The total workload and achievement rate of the workload calculated before experiments involving each group were used for analysis. The cadence was decided to be insufficient if the workload during the 3-week period did not reach $90 \%$ of the workload calculated prior to the experiments; these data were excluded from the analysis. The average value of the absolute load of the HIICT during the training period is shown in Table 1.

Table 1. Average value of the absolute load of high-intensity intermittent cycling training during the training period.

\begin{tabular}{cccccc}
\hline Group & Session & 1-2 set (kp) & 3-4 set (kp) & 5-6 set (kp) & 7-8 set (kp) \\
\hline \multirow{3}{*}{$60 \mathrm{rpm}$} & 1-3 session & $6.2 \pm 0.4$ & $5.9 \pm 0.4$ & $5.7 \pm 0.4$ & $5.4 \pm 0.4$ \\
& 4-6 session & $6.3 \pm 0.4$ & $6.1 \pm 0.4$ & $5.8 \pm 0.4$ & $5.5 \pm 0.4$ \\
& 7-9 session & $6.5 \pm 0.4$ & $6.2 \pm 0.4$ & $6.0 \pm 0.4$ & $5.7 \pm 0.4$ \\
\hline \multirow{3}{*}{$120 \mathrm{rpm}$} & 1-3 session & $3.1 \pm 0.2$ & $2.9 \pm 0.2$ & $2.8 \pm 0.2$ & $2.7 \pm 0.2$ \\
& 4-6 session & $3.1 \pm 0.2$ & $3.0 \pm 0.2$ & $2.9 \pm 0.2$ & $2.8 \pm 0.2$ \\
& 7-9 session & $3.2 \pm 0.2$ & $3.1 \pm 0.2$ & $3.0 \pm 0.2$ & $2.8 \pm 0.2$ \\
\hline
\end{tabular}

$\mathrm{VO}_{2 \max }$ alues are mean \pm SD. $60 \mathrm{rpm}$, High-intensity intermittent cycling training with $60 \mathrm{rpm}$; $120 \mathrm{rpm}$, Highintensity intermittent cycling training with $120 \mathrm{rpm}$.

\subsection{Statistical Analyses}

All data are presented as means and standard deviations (SD). Total workload, achievement rate, baseline $\mathrm{VO}_{2 \max }$ levels, and percent change of $\mathrm{VO}_{2 \max }$ in both study groups were analyzed using the unpaired $t$-test. Moreover, the changes in $\mathrm{VO}_{2 \max }$ and body weight from pre- to post-training were analyzed by two-way (group $\times$ time) mixed-design analysis of variance (ANOVA; between-participant factor: group, within-participant factor: time). A post hoc analysis was performed using the Bonferroni test. The statistical significance level was set at $p<0.05$. As indices of the effect size, Cohen's d (for unpaired $t$-test and post hoc comparisons) and partial $\eta^{2}$ (for ANOVA) were also calculated. SPSS Statistics (version 24.0 for Windows, SPSS Inc., Chicago, IL, USA) was used for data analysis.

\section{Results}

All 18 participants who completed the nine training sessions exceeded the $90 \%$ achievement rate of the workload calculated prior to the experiments. No significant differences in the baseline $\mathrm{VO}_{2 \max }$ levels were found between the groups $(p=0.967$, Cohen's d =0.020, $60 \mathrm{rpm}: 59.2 \pm 3.9 \mathrm{~mL} / \mathrm{kg} / \mathrm{min}$, $120 \mathrm{rpm}: 59.3 \pm 5.5 \mathrm{~mL} / \mathrm{kg} / \mathrm{min}$ ). The total workload and achievement rate of the workload calculated 
before the experiments for each group are shown in Table 2. No significant differences in the total workload and achievement rate of the workload were found between the groups.

Table 2. Comparisons of total workload and achievement rate during the training period.

\begin{tabular}{ccccc}
\hline & $\mathbf{6 0} \mathbf{~ r p m}$ & $\mathbf{1 2 0} \mathbf{~ r p m}$ & $\boldsymbol{p}$ Value & Cohen's d \\
\hline Total workload (W) & $25,234.7 \pm 1572.8$ & $24,897.1 \pm 1757.5$ & 0.673 & 0.202 \\
Achievement rate (\%) & $98.3 \pm 1.0$ & $97.9 \pm 1.4$ & 0.522 & 0.309
\end{tabular}

Values are mean \pm SD. 60 rpm, High-intensity intermittent cycling training with 60 rpm; 120 rpm, High-intensity intermittent cycling training with $120 \mathrm{rpm}$.

The main effects of time and interaction were not observed in body weight (main effect of time: $p=0.821$, partial $\eta^{2}=0.03$, interaction: $p=0.821$, partial $\eta^{2}=0.03,60 \mathrm{rpm}$ pre-training: $65.4 \pm 3.9 \mathrm{~kg}$, $60 \mathrm{rpm}$ post-training: $65.4 \pm 3.8 \mathrm{~kg}, 120 \mathrm{rpm}$ pre-training: $64.4 \pm 6.3 \mathrm{~kg}, 120 \mathrm{rpm}$ post-training: $64.3 \pm 5.9 \mathrm{~kg}$ ). Results in terms of change in $\mathrm{VO}_{2 \max }$ from pre- to post-training between groups are shown in Figure 1. The main effect of time was observed in $\mathrm{VO}_{2 \max }\left(p=0.016\right.$, partial $\left.\eta^{2}=0.311\right)$. However, no interaction was observed $\left(p=0.680\right.$, partial $\left.\eta^{2}=0.011\right)$. No significant difference was detected in the relative change of $\mathrm{VO}_{2 \max }(p=0.675$, Cohen's $\mathrm{d}=0.201,60 \mathrm{rpm}: 4.3 \pm 6.2 \%, 120 \mathrm{rpm}$ : $3.2 \pm 5.5 \%$ ). The average values of $\mathrm{VO}_{2 \max }$ were as follows: $60 \mathrm{rpm}$ pre-training: $59.2 \pm 3.9 \mathrm{~mL} / \mathrm{kg} / \mathrm{min}$, $60 \mathrm{rpm}$ post-training: $61.7 \pm 4.4 \mathrm{~mL} / \mathrm{kg} / \mathrm{min}$, and $120 \mathrm{rpm}$ pre-training: $59.3 \pm 5.5 \mathrm{~mL} / \mathrm{kg} / \mathrm{min}, 120 \mathrm{rpm}$ post-training: $61.1 \pm 6.1 \mathrm{~mL} / \mathrm{kg} / \mathrm{min}$.

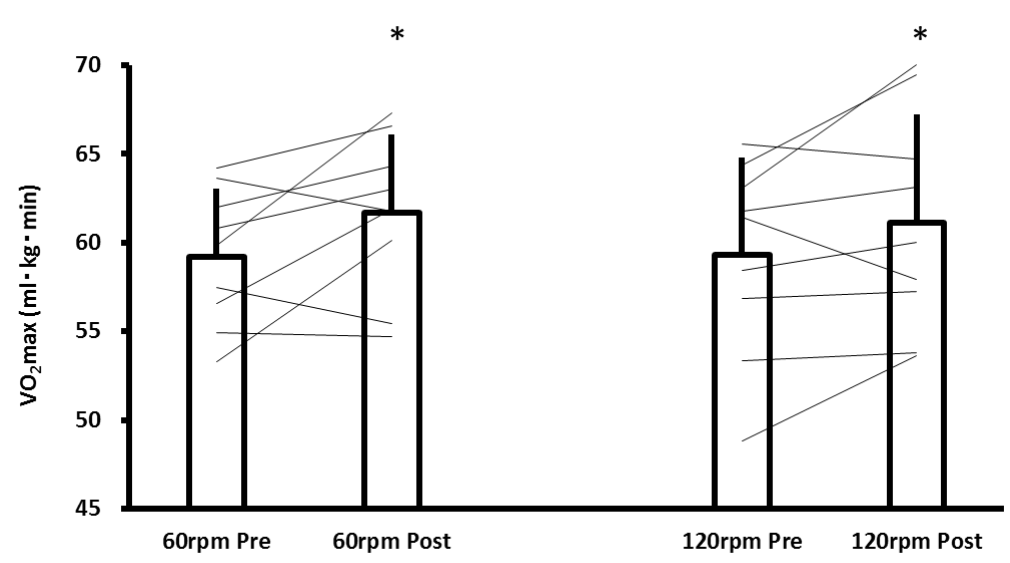

Figure 1. Change of $\mathrm{VO}_{2 \mathrm{max}}$ from pre- to post-training in $60 \mathrm{rpm}$ and $120 \mathrm{rpm}$. Each line represents the change for an individual participant. Bars are the average value for all participants. Error bars are the standard deviation. ${ }^{*} p<0.05$ vs pre-training in each group. $60 \mathrm{rpm}$ : high-intensity intermittent cycling training with $60 \mathrm{rpm} ; 120 \mathrm{rpm}$ : high-intensity intermittent cycling training with $120 \mathrm{rpm}$.

\section{Discussion}

To the best of the author's knowledge, this is the first study to examine whether 3-week workmatched HIICT with a high cadence $(120 \mathrm{rpm})$ significantly improves $\mathrm{VO}_{2 \max }$ in university athletes, compared to a low cadence $(60 \mathrm{rpm})$. As a result of a 3-week training period, $\mathrm{VO}_{2 \max }$ increased similarly for $60 \mathrm{rpm}$ and $120 \mathrm{rpm}$ from pre- to post-training. These results were contrary to our hypothesis.

There are two possibilities explaining why there was no significant difference in the effect on $\mathrm{VO}_{2 \mathrm{max}}$ between $60 \mathrm{rpm}$ and $120 \mathrm{rpm}$ in this study. First, the $\mathrm{VO}_{2}$ response during the HIICT in this study may be similar for $60 \mathrm{rpm}$ and $120 \mathrm{rpm}$, unlike the different responses seen in previous studies [15-20]. In many previous studies, $\mathrm{VO}_{2}$ was higher during work-matched cycling exercise with a high cadence than a low cadence [15-20]. However, submaximal exercise intensity was used in these studies, while a much higher supramaximal intensity was used in this study. Recruitment of type II fiber has been shown to be increased at a low cadence compared to a high cadence during 
submaximal cycling [29,30], and type II fiber has higher ATP consumption than type I fiber [31]. In this study, $\mathrm{VO}_{2}$ responses might be similar between $60 \mathrm{rpm}$ and $120 \mathrm{rpm}$ due to the recruitment of more intense type II fibers than in previous studies by using supramaximal intensity. Future studies should investigate in detail the acute $\mathrm{VO}_{2}$ response during work-matched HIICT with different cadences.

The second possibility is that workload, rather than exercise intensity, affects $\mathrm{VO}_{2 \max }$. In this study, if $\mathrm{VO}_{2}$ during $\mathrm{HIICT}$ with a high cadence was higher than with a low cadence like in many previous studies, HIICT with a high cadence was higher in actual intensity compared to that with a low cadence, even though their relative intensity (e.g., $\% \mathrm{VO}_{2 \max }$ ) were the same. Matsuo et al. reported that high-intensity training improves $\mathrm{VO}_{2 \max }$ more significantly than moderate-intensity training due to increased left ventricular mass and stroke volume [21]. On the other hand, Scribbans et al. [32] reported in their meta-analysis that increasing exercise intensity above $60 \% \mathrm{VO}_{2 \max }$ does not provide additional increases in $\mathrm{VO}_{2 \max }$. In addition, Granata et al. [23] reported that $\mathrm{VO}_{2 \max }$ can be changed by manipulating the total workload, not the relative intensity. Therefore, the similar chronic effect on $\mathrm{VO}_{2 \max }$ in this study might be related to the equal workload in both groups.

In this study, the subjects had relatively high initial $\mathrm{VO}_{2 \max }$ levels $(60 \mathrm{rpm}: 59.2 \pm 3.9 \mathrm{~mL} / \mathrm{kg} / \mathrm{min}$, $120 \mathrm{rpm}: 59.3 \pm 5.5 \mathrm{~mL} / \mathrm{kg} / \mathrm{min}$ ) as compared to previous studies, in which the increase in $\mathrm{VO}_{2 \max }$ was observed following a short training period (32.8-57.3 $\mathrm{mL} / \mathrm{kg} / \mathrm{min}$ ) [3-9]. Nevertheless, $\mathrm{VO}_{2 \max }$ significantly increased in both groups after the 3-week training period. This implies that, for regularly trained athletes, the 3-week HIICT protocol used in this study appears to be an effective method to improve $\mathrm{VO}_{2 \max }$ in the short term, regardless of cadences used during the HIICT.

\section{Conclusions}

We examined whether 3-week work-matched HIICT with a high cadence (120 rpm) significantly improves $\mathrm{VO}_{2 \max }$ in university athletes compared to HIICT with a low cadence $(60 \mathrm{rpm})$. Following a 3-week training period, contrary to our hypothesis, $\mathrm{VO}_{2 \max }$ increased similarly in groups using a cadence of $60 \mathrm{rpm}$ or $120 \mathrm{rpm}$. These results suggest that cadence during 3-week work-matched $\mathrm{HIICT}$ is not training variable affecting the short-term effect of $\mathrm{VO}_{2 \max }$ in university athletes.

Author Contributions: N.T. conceived, designed, and carried out all experiments, performed statistical analyses and wrote manuscript; K.T., K.S. and M.M. reviewed and provided feedback for approval of the final manuscript draft. All authors have read and approved the manuscript.

Funding: This research received no external funding.

Acknowledgments: The authors thank the athletes for their participation.

Conflicts of Interest: The authors declare no conflicts of interest.

\section{References}

1. Milanović, Z.; Sporiš, G.; Weston, M. Effectiveness of High-Intensity Interval Training (HIT) and Continuous Endurance Training for $\mathrm{VO}_{2 \max }$ Improvements: A Systematic Review and Meta-Analysis of Controlled Trials. Sports Med. 2015, 45, 1469-1481. [CrossRef] [PubMed]

2. Gillen, J.B.; Gibala, M.J. Is high-intensity interval training a time-efficient exercise strategy to improve health and fitness? Appl. Physiol. Nutr. Metab. 2014, 39, 409-412. [CrossRef] [PubMed]

3. Tabata, I.; Nishimura, K.; Kouzaki, M.; Hirai, Y.; Ogita, F.; Miyachi, M.; Yamamoto, K. Effects of moderateintensity endurance and high-intensity intermittent training on anaerobic capacity and $\mathrm{VO}_{2 \max }$. Med. Sci. Sports Exerc. 1996, 28, 1327-1330. [CrossRef] [PubMed]

4. Talanian, J.L.; Galloway, S.D.; Heigenhauser, G.J.; Bonen, A.; Spriet, L.L. Two weeks of high intensity aerobic interval training increases the capacity for fat oxidation during exercise in women. J. Appl. Physiol. 2007, 102, 1439-1447. [CrossRef] [PubMed]

5. Rodas, G.; Ventura, J.; Cadefau, J.; Cussó, R.; Parra, J. A short training programme for the rapid improvement of both aerobic and anaerobic metabolism. Eur. J. Appl. Physiol. 2000, 82, 480-486. [CrossRef] [PubMed]

6. Whyte, L.J.; Gill, J.M.; Cathcart, A.J. Effect of 2 weeks of sprint interval training on health-related outcomes in sedentary overweight/obese men. Metabolism 2010, 59, 1421-1428. [CrossRef] [PubMed] 
7. Hazell, T.J.; MacPherson, R.E.; Gravelle, B.M.; Lemon, P.W. 10 or 30-s sprint interval training bouts enhance both aerobic and anaerobic performance. Eur. J. Appl. Physiol. 2010, 110, 153-160. [CrossRef] [PubMed]

8. Bayati, M.; Farzad, B.; Gharakhanlou, R.; Agha-Alinejad, H. A practical model of low-volume high-intensity interval training induces performance and metabolic adaptations that resemble 'all-out' sprint interval training. J. Sports Sci. Med. 2011, 10, 571-576. [PubMed]

9. Astorino, T.A.; Allen, R.P.; Roberson, D.W.; Jurancich, M. Effect of high-intensity interval training on cardiovascular function, $\mathrm{VO}_{2 \max }$, and muscular force. J. Strength Cond. Res. 2012, 26, 138-145. [CrossRef] [PubMed]

10. Viana, R.B.; de Lira, C.A.B.; Naves, J.P.A.; Coswig, V.S.; Del Vecchio, F.B.; Gentil, P. Tabata protocol: A review of its application, variations and outcomes. Clin. Physiol. Funct. Imaging 2018. [CrossRef] [PubMed]

11. Ericson, M.O.; Nisell, R. Tibiofemoral joint forces during ergometer cycling. Am. J. Sports Med. 1986, 14, 285-290. [CrossRef] [PubMed]

12. Fleming, B.C.; Beynnon, B.D.; Renstrom, P.A.; Peura, G.D.; Nichols, C.E.; Johnson, R.J. The strain behavior of the anterior cruciate ligament during bicycling. An in vivo study. Am. J. Sports Med. 1998, 26, 109-118. [CrossRef] [PubMed]

13. Bijker, K.; de Groot, G.; Hollander, A. Differences in leg muscle activity during running and cycling in humans. Eur. J. Appl. Physiol. 2002, 87, 556-561. [CrossRef] [PubMed]

14. Hansen, E.A.; Rønnestad, B.R. Effects of Cycling Training at Imposed Low Cadences: A Systematic Review. Int. J. Sports Physiol. Perform. 2017, 12, 1127-1136. [CrossRef] [PubMed]

15. Kang, J.; Hoffman, J.R.; Wendell, M.; Walker, H.; Hebert, M. Effect of contraction frequency on energy expenditure and substrate utilisation during upper and lower body exercise. Br. J. Sports Med. 2004, 38, 31-35. [CrossRef] [PubMed]

16. Skovereng, K.; Ettema, G.; van Beekvelt, M.C.P. Oxygenation, local muscle oxygen consumption and joint specific power in cycling: The effect of cadence at a constant external work rate. Eur. J. Appl. Physiol. 2016, 116, 1207-1217. [CrossRef] [PubMed]

17. Skovereng, K.; Ettema, G.; Van Beekvelt, M. The Effect of Cadence on Shank Muscle Oxygen Consumption and Deoxygenation in Relation to Joint Specific Power and Cycling Kinematics. PLoS ONE 2017, 12, e0169573. [CrossRef] [PubMed]

18. Kounalakis, S.N.; Geladas, N.D. Cardiovascular drift and cerebral and muscle tissue oxygenation during prolonged cycling at different pedalling cadences. Appl. Physiol. Nutr. Metab. 2012, 37, 407-417. [CrossRef] [PubMed]

19. Hirano, M.; Shindo, M.; Mishima, S.; Morimura, K.; Higuchi, Y.; Yamada, Y.; Higaki, Y.; Kiyonaga, A. Effects of 2 weeks of low-intensity cycle training with different pedaling rates on the work rate at lactate threshold. Eur. J. Appl. Physiol. 2015, 115, 1005-1013. [CrossRef] [PubMed]

20. Francescato, M.P.; Girardis, M.; Di Prampero, P.E. Oxygen cost of internal work during cycling. Eur. J. Appl. Physiol. 1995, 72, 51-57. [CrossRef]

21. Matsuo, T.; Saotome, K.; Seino, S.; Shimojo, N.; Matsushita, A.; Iemitsu, M.; Ohshima, H.; Tanaka, K.; Mukai, C. Effects of a low-volume aerobic-type interval exercise on $\mathrm{VO}_{2 \max }$ and cardiac mass. Med. Sci. Sports Exerc. 2014, 46, 42-50. [CrossRef] [PubMed]

22. Paton, C.D.; Hopkins, W.G.; Cook, C. Effects of low- vs. high-cadence interval training on cycling performance. J. Strength Cond. Res. 2009, 23, 1758-1763. [CrossRef] [PubMed]

23. Granata, C.; Oliveira, R.S.; Little, J.P.; Renner, K.; Bishop, D.J. Mitochondrial adaptations to high-volume exercise training are rapidly reversed after a reduction in training volume in human skeletal muscle. FASEB J. 2016, 30, 3413-3423. [CrossRef] [PubMed]

24. Takizawa, K.; Yamaguchi, T.; Shibata, K. Warm-up exercises may not be so important for enhancing submaximal running performance. J. Strength Cond. Res. 2018, 32, 1383-1390. [CrossRef] [PubMed]

25. Takizawa, K.; Yamaguchi, T.; Shibata, K. The effects of short-duration static stretching of the lower extremities after warm-up exercise on endurance running performance. Mov. Health Exerc. 2015, 4, 37-49. [CrossRef]

26. Yamaguchi, T.; Takizawa, K.; Shibata, K. Acute effect of dynamic stretching on endurance running performance in well-trained male runners. J. Strength Cond. Res. 2015, 29, 3045-3052. [CrossRef] [PubMed]

27. Tabata, I.; Irisawa, K.; Kouzaki, M.; Nishimura, K.; Ogita, F.; Miyachi, M. Metabolic profile of high intensity intermittent exercises. Med. Sci. Sports Exerc. 1997, 29, 390-395. [CrossRef] [PubMed] 
28. Oliveira, M.F.M.D.; Caputo, F.; Corvino, R.B.; Denadai, B.S. Short-term low-intensity blood flow restricted interval training improves both aerobic fitness and muscle strength. Scand. J. Med. Sci. Sports 2016, 26, 1017-1025. [CrossRef] [PubMed]

29. Ahlquist, L.E.; Bassett, D.R.; Sufit, R.; Nagle, F.J.; Thomas, D.P. The effect of pedaling frequency on glycogen depletion rates in type I and type II quadriceps muscle fibers during submaximal cycling exercise. Eur. J. Appl. Physiol. 1992, 65, 360-364. [CrossRef]

30. Deschenes, M.R.; Kraemer, W.J.; McCoy, R.W.; Volek, J.S.; Turner, B.M.; Weinlein, J.C. Muscle recruitment patterns regulate physiological responses during exercise of the same intensity. Am. J. Physiol. Regul. Integr. Comp. Physiol. 2000, 279, R2229-R2236. [CrossRef] [PubMed]

31. Han, Y.S.; Proctor, D.N.; Geiger, P.C.; Sieck, G.C. Reserve capacity for ATP consumption during isometric contraction in human skeletal muscle fibers. J. Appl. Physiol. 2001, 90, 657-664. [CrossRef] [PubMed]

32. Scribbans, T.D.; Vecsey, S.; Hankinson, P.B.; Foster, W.S.; Gurd, B.J. The Effect of Training Intensity on $\mathrm{VO}_{2 \mathrm{max}}$ in Young Healthy Adults: A Meta-Regression and Meta-Analysis. Int. J. Exerc. Sci. 2016, 9, 230-247. [PubMed]

(C) 2018 by the authors. Licensee MDPI, Basel, Switzerland. This article is an open access article distributed under the terms and conditions of the Creative Commons Attribution (CC BY) license (http:/ / creativecommons.org/licenses/by/4.0/). 